\title{
The Effect of Customer Aggression on Burnout
}

\author{
Salih Dursun \\ Karadeniz Technical University, Trabzon, Turkey, Department of Labour Economics and Industrial Relations \\ Email: sdursun@ktu.edu.tr

\section{Serpil Aytac}

Uludağ University, Bursa, Turkey, Department of Labour Economics and Industrial Relations

Email: saytac@uludag.edu.tr

\section{Doi:10.5901/ajis.2014.v3n4p369}

\begin{abstract}
The service sector is currently the fastest growing economic sector. However, for employees in this sector, the high level of customer interaction may be the reason for undesired consequences such as customer aggression. This study aimed to demonstrate the effect on the burnout level of bank employees exposed to verbal abuse. The study sample comprised 161 employees of private banks sector. The mean age of the study participants was $32.20 \pm 5.79$ years and the mean duration of employment was $7.63 \pm 5.79$ years. In the data analysis, , correlation and regression analysis were used. From the results of the analyses, the finding was obtained that verbal abuse signficantly increased the emotional burnout and depersonalization levels of bank employees.
\end{abstract}

Keywords: customer agression, verbal abuse, burnout, bank employees

\section{Introduction}

The service sector has become the fastest growing sector in both developed and developing countries. According to 2009 data, the service sector accounts for $72 \%$ of total employment in OECD countries (Turkish Statistical Institute [TUIK], 2011). Although the service sector in Turkey lags behind that of OECD countries, it is one of the rapidly growing sectors in parallel with global development. While the service sector in Turkey comprised $37.7 \%$ of total employment in 1990, according to TUIK November 2012 data, employment in the service sector had reached 50\% (TUIK, 2013).

Together with this increase in the service sector, so competition has increased between companies operating in this sector. To this end, 'customer service quality' has become one of the most important indicators of competitive advantage for the great majority of organizations in the service sector (Richards \& Schat, 2007). Thus in today's customer-focused competitive world, customer aggression has negative effects on concepts such as 'the customer is always right' and 'the customer is king' and also on the health and safety of the employees under attack (Richards \& Schat, 2007; Ben-Zur \& Yagil, 2005).

Although aggression in the workplace may be exhibited through different forms of behavior, the vast majority of studies on workplace aggression have concentrated on aggressive behavior of management to employees and employee to employee (Ben-Zur \& Yagil, 2005). However, those working in customer service spend more time interacting with customers rather than management or colleagues. Therefore, the relationship between customers and employees is just as important as the relationship with management or co-workers (Dormann \& Zapf, 2004).

Customer aggression is a significant organizational problem in modern working life, particularly for employees in the service sector who are in direct contact with customers. In the context of a service, it is possible to define customer aggression as a customer's behavior aimed at harming or discomfiting those giving service. This definition includes some sub-dimensions. Firstly, customer aggression is seen in a wide area such as retail sales, restaurants, hotels, airlines and railways, call centers and the banking sector. Secondly, psychological aggression (shouting, gestures, threats etc.) and physical violence (physical attacks), which harm employees both physically and psychologically, must be considered in the framework of a series of behaviors. Thirdly, just as the interaction between customer and employee may be direct face-to-face interaction, it may also occur in the form of service given via e-mail or telephone (Bedi \& Schat, 2007).

On the other hand, just as aggressive behavior by the customer may be psychological, such as rudeness, verbal abuse or hostile behavior (shouting, swearing etc.) and threats, it may also be in the form of physical aggression including 
violent actions (Richards \& Schat, 2007). However widespread customer aggression has been shown to be, it cannot be said to occur in every sector. In a study by Boyd (2002), it was reported that $53 \%$ of employees in the airline and railways sector had been exposed to verbal abuse in the previous 12 months. According to the results of a study by Akgeyik and Gungor (2010), $77,2 \%$ of supermarket cashier, $85,2 \%$ of call center operator and $64,5 \%$ of sales clerk employees had suffered customer violence at least once in their career.

Customer aggression has a negative effect on the employee's health and safety. According to studies conducted on this subject, the individual feels worthless and levels of depression and stress increase (Boyd, 2002) causing somatic symptoms of emotional burnout and emotional dissonance (Bedi \& Schat, 2007; Grandey, Dickter \& Sin, 2004 ).

These types of aggressive events have an effect on an individual's involvement and behavior related to work. These go from dissatisfaction and decreased organizational attachment, low morale and motivation to absence from work (Yagil, 2008). Increased rates of turnover in the labor force, decreased employee performance, increased unease between employees, increased absence because of illness or on request are only a few of the negative consequences of this kind of behavior from an organizational perspective.

This study aimed to evaluate the effects of verbal abuse from customers on the burnout levels of bank employees.

\section{Method}

\subsection{Data Collection}

Verbal Abuse Scale: The scale used in the measurement of verbal abuse directed at employees was the social stresses scale related to customers which was developed by Dormann and Zapf (2004), consisting of 5 questions of the verbal abuse dimension. The items in the scale are of a 5-point Likert type with answers varying from 'never true' to 'always true'.

Burnout Scale: The Maslach Burnout Scale, which was developed by Maslach and Jackson (1986) was used in the study. The scale consists of 22 items in the 3 sub-dimensions of emotional burnout, depersonalization and low personal accomplishment. The items in the scale are of a 5-point Likert type with answers varying from 'never' to 'always'.

\subsection{Participants}

The study was conducted on bank employees. According to December 2012 data from the Turkish Banking Association, there were a total of 186,120 employees in 10,234 branches of 45 banks in Turkey.

The study sample consisted of 161 employees working in different private sector banks. Questionnaires were delivered in sealed envelopes, completed by voluntary participants and collected one week later. Of 200 distributed questionnaires, 175 were returned (return rate, 85\%) and 14 were excluded from the study due to incomplete data.

\section{Results}

The mean age of the study participants was $32.20 \pm 5.79$ years (mean \pm standard deviation), ranging from $21-50$ years. The mean duration of employment in the bank was $7.63 \pm 5.79$ years. $51.6 \%$ of the participants were female and $48.4 \%$ were male. Educational status of the participants was determined as $78 \%$ university graduates, $14.3 \%$ high school and $12 \%$ postgraduates. Marital status was $55.6 \%$ married and $44.4 \%$ single.

The results of the reliability analysis of the scales used are shown in Table 1.

Table 1. The Results of The Reliability Analysis Of The Scales

\begin{tabular}{lccc}
\hline \multicolumn{1}{c}{ Variables } & Item & Mean. $\mathbf{c S D}$ & C.Alpha \\
\hline Burnout & & & \\
Emotional burnout & 9 & $21,14 \pm 6,36$ & 0,88 \\
Depersonalization & 5 & $9,38 \pm 3,44$ & 0,75 \\
Personal accomplishment & 8 & $29,42 \pm 4,48$ & 0,78 \\
\hline \multicolumn{1}{r}{ Verbal Abuse } & 5 & $7,11 \pm 2,72$ & 0,87 \\
\hline
\end{tabular}

As shown in Table 1, the reliability coefficients of both the scales used varied between 0.75 and 0.88 and were therefore within acceptable social sciences limits. 
Table 2. Results of The Correlation Between Variables

\begin{tabular}{lcccc}
\hline 1. Verbal abuse & 1 & 2 & 3 & 4 \\
2.Emotional Burnout & 1 & & & \\
3.Depersonalization &, $265^{* *}$ & 1 & & \\
4.Personal accomplishment &, $241^{* \star}$ &, $618^{* \star}$ & 1 & \\
$* \mathrm{p} p<0.01$ &,- 092 &,$- 235^{\star *}$ & $-291^{* \star}$ & 1 \\
\hline
\end{tabular}

The results of the correlation analysis between variables are shown in Table 2. When the correlation analysis results of verbal abuse and the burnout dimension were examined, a positive significant relationship was seen between verbal abuse and emotional burnout $(r=0.26 ; p<0.01)$ and depersonalization $(r=0.24 ; p<0.01)$. No significant relationship was determined between verbal abuse and personal accomplishment one of the dimensions of burnout $(p>0.05)$.

Table 3. Results of The Regression Analysis of The Effect of Verbal Abuse on Burnout

\begin{tabular}{cccc}
\hline Variables & Emotional burnout & Depersonalization & Personal accomplishment \\
\hline Verbal abuse &, $265^{1}$ &, 241 &,-092 \\
\hline$R^{2}$ & 0,07 & 0,05 & 0,008 \\
\hline $\mathrm{F}$ & $11,997^{\star \star}$ & $9,843^{\star \star}$ & 1,357 \\
\hline${ }^{* \star} \mathrm{p}<0.01 ;{ }^{1}$ All coefficients are standardized. & &
\end{tabular}

According to Table 3, in the model established for emotional burnout, $7 \%$ is explained by total variables, $5 \%$ by depersonalization, and $0.8 \%$ by personal accomplishment. In the regression analysis performed to explain the emotional burnout levels of the employees, the variable of verbal abuse was found to be statistically significant. Thus, verbal abuse caused an increase in the level of emotional burnout $(p<0.01)$. In the regression analysis performed to explain the depersonalization levels of the burnout dimension of the employees, the variable of verbal abuse was found to be statistically significant $(p<0.01)$. Therefore, an increase in verbal abuse directed at employees caused an increase in levels of depersonalization. No significance was found in the regression model established to explain personal accomplishment levels of the employees ( $p>0.05)$.

\section{Discussion}

Aggression in working life causes significant problems for an individual's health and safety. Although employees in every sector are at risk of being exposed to aggressive behavior, the risk is much greater for employees in the service sector. There is increased risk of violence more often in interaction with people outside the workplace for employees in this sector. The high level of interaction with customers brings with it the risk of exposure to aggressive behavior for employees in the banking sector. Significant findings of the analyses performed in this study show the effect on burnout levels of bank employees who suffer verbal abuse.

According to the analysis results of the current study, customer verbal abuse was determined to have a significant positive effect on emotional burnout and insensitivity $(p<0.05)$. Thus with increased customer verbal abuse the emotional burnout and depersonalization levels of the bank employees also increased. No significant effect of customer verbal abuse was found on personal accomplishment $(p>0.05)$. Similar findings have been reported from other previous studies on this subject in the service sector. For example, in a study by Grandey, Dickter and Sin (2004) of call center employees, a significant positive relationship was determined between the frequency of customer aggression and emotional burnout. In a similar study by Dierendonck and Mevisen (2002) of tram drivers, a significant relationship was determined between aggressive behavior and burnout. Dormann and Zapft studied different occupations (airline staff, travel agency employees, sales personnel) in the service sector and a significant positive relationship was determined between customer verbal abuse and emotional burnout and depersonalization while a significant negative relationship was determined between customer verbal abuse and personal accomplishment. A study of hotel workers by Karatepe, Yorganci and Haktanir (2009) and in a study of travel agency, hotel and restaurant employees by Kim, Paek, Choi and Lee (2009), results were obtained demonstrating that customer verbal abuse significantly increased emotional burnout. In another study by Ben-Zur and Yagil (2005), it was determined that customer aggression increased employees' levels of emotional burnout and depersonalization. In the same study the burnout dimensions of customer aggression were not 
found to have any significant effect on personal accomplishment.

\section{References}

Akgeyik, T. and Gungor, M. (2010). Profile of Perpetrators of Customer Aggression (a Survey among Front-Line Call-Center and Retail Staff), European Journal of Management, 10(3):95-101.

Bedi, A. and Schat, A. C. H. (2007). Customer Aggression: A Theoretical And Meta -Analytic Review, ASAC, 115-127.

Ben-Zur, H. and Yagil, D. (2005). The relationship between empowerment, aggressive behaviors of customers, coping, and burnout. European Journal of Work and Organizational Psychology, 14: 81-99.

Boyd, C. (2002). Customer violence and employee health and safety. Work, Employment and Society, 16: 151-169.

Dierendonck, D. van and Mevissen, N. (2002). Aggressive Behavior of Passengers, Conflict Management Behavior, and Burnout Among Trolley Car Drivers", International Journal of Stress Management, 9(4):345-355.

Dormann, C. and Zapf, D. (2004). Customer-related social stressors and burnout. Journal of Occupational Health Psychology, 9: 61-82.

Grandey, A. A.; Dickter, D. N. A and Sin, H-P. (2004). The Customer is not Always Right: Customer Aggression and Emotion Regulation of Service Employees, Journal of Organizational Behavior, 25:1-22.

Karatepe, O. M., Yorganci, I. and Haktanir, M. (2009), An Investigation of the Role of Job Resources in Mitigating Customer-Related Social Stressors and Emotional Exhaustion, Services Marketing Quarterly, 31(1):72-88.

Kim, T. T., Paek, S. Choi, C. H. and Lee, G. (2012). Frontline service employees' customer-related social stressors, emotional exhaustion, and service recovery performance: customer orientation as a moderator, Serv. Bus., 6:503-526.

Richards, David A. and Schat, Aaron C. H. (2007). Attachment and Customer Aggression:An Affective Events Theory Model, ASAC, 253-269.

Turkish Statistical Institute (TUIK), Retrieved January 30, 2013, from http://www.tuik.gov.tr/PreTablo.do?alt_id=25.

Turkish Statistical Institute (TUIK). Household Labour Force Statistics 2011.

Yagil, D. (2008). When the customer is wrong: A review of research on aggression and sexual harassment in service encounters, Aggression and Violent Behavior , 13:141-152. 